\title{
Anoreksiya Nervosalı Hastalarda İntestinal Mikrobiyotanın Rolü
}

\author{
Role of Intestinal Microbiota in Patients with Anorexia Nervosa \\ ๑ Negin Almasi ${ }^{1}$, ๑ Arzu Kabasakal Çetin ${ }^{1}$, ๑ Zeynep Göktaş ${ }^{1}$ \\ 1Hacettepe Üniversitesi, Ankara, Türkiye
}

Düşük vücut ağırlığı, bozulmuş beden algısı ve kilo alma korkusu ile karakterize psikiyatrik bir bozukluk olan anoreksiya nervozanın etiyopatogenezi tam olarak bilinmemektedir. Literatürde yer alan çalışmalar anoreksiya nervosalı hastalarda beslenme tedavisinin ve yeniden ağırlık kazanımının intestinal disbiyoz yönetiminde yeterince etkin olmadığını göstermektedir, ancak çalışmaların sonuçları çelişkilidir. Bu derlemede intestinal mikrobiyotanın anoreksiya nervosa patofizyolojisindeki olası rolü, anoreksiya nervosalı hastalarda intestinal disbiyoza ilişkin özellikler ve intestinal mikrobiyota yönetiminde olası tedavi yaklaşımları hakkında bilgi verilmesi amaçlanmıştır.

Anahtar Sözcükler: Anoreksiya nervoza, mikrobiyota, disbiyoz

Anorexia nervosa is a psychiatric disorder characterized by severe low body weight, impaired self-body image, and intense fear of gaining weight, however its etiopathogenesis is not fully known. Some studies show that nutritional rehabilitation and corresponding weight restoration are not effective enough in the management of intestinal dysbiosis in patients with anorexia nervosa, but results are inconclusive. This work aims to review the existing studies to provide information about the possible role of intestinal microbiota in the pathophysiology of anorexia nervosa, characteristics of intestinal dysbiosis in patients with anorexia nervosa, and possible treatment approaches in the management of intestinal microbiota.

Keywords: Anorexia nervosa, microbiota, dysbiosis

Anoreksiya nervosa DSM-5 kriterlerine göre düşük vücut ağırlığı, bozulmuş beden algısı ve kilo alma korkusu ile karakterizedir ve kısıtlayıcı tip ve çıkartma tipi anoreksiya nervosa olmak üzere iki gruba ayrılmaktadır (APA 2013). Ağırlık kaybı ve besin alımının kısıtlanması metabolik, kardiyopulmoner, endokrin, gastrointestinal ve hematolojik komplikasyonlara yol açmaktadır (Cass ve ark. 2020) Anoreksiya nervosanın yaşam boyu prevalansının kadınlarda \%1.4, erkeklerde ise \%0.6 olduğu bildirilmiştir (Galmiche ve ark. 2019). Yeme davranışı bozukluklarının mortalite oranları değerlendirildiğinde, anoreksiya nervosanın en yüksek mortalite oranına sahip olduğu görülmektedir (Arcelus ve ark. 2019). Anoreksiya nervosanın etiyolojisi tam olarak bilinmemekle birlikte gelişiminde biyolojik, psikolojik ve sosyal faktörlerin rol oynadığı düşünülmektedir (Erbay ve ark. 2016, Moskowitz ve ark. 2017). Genetik faktörler ile anksiyete, obsesyon ve mükemmeliyetçilik gibi kişilik özelliklerinden oluşan nörobiyolojik risk faktörleri anoreksiya nervosanın patogenezinde önemli rol oynamaktadır (Kaye ve ark. 2013). Beyin görüntüleme tekniklerinin gelişimi, epigenetik yaklaşımlar, hayvan modelleri ile yapılan çalışmalar, yeni nöropeptidlerin keşfi ve intestinal mikrobiyotada meydana gelen değişiklikler anoreksiya nervosanın patofizyolojisi ile ilgili daha kapsamlı modellerin öne sürülmesine olanak sağlamıştır (Gorwood ve ark. 2016). İntestinal mikrobiyotada meydana gelen değişikliklerin beyin-barsak aksında bozulmalara yol açarak anoreksiya nervosa patofizyolojisinde rol oynayabileceği düşünülmektedir (Di Lodovico ve ark. 2020). Anoreksiya nervosa tedavisinde farmakoterapinin etkinliği oldukça sınırlıdır ve psikoterapötik müdahalelerin ise orta düzeyde etkinlik gösterdiği bilinmektedir (Öyekçin ve ark. 2011, Herpertz-Dahlmann ve ark. 2015, Okumuş ve ark. 2016). Bu durum, ilaç tedavisi ile psikoterapötik uygulamalara ek olarak yeni tedavi yaklaşımlarının geliştirilmesini elzem hale getirmektedir. Anoreksiya nervosalı hastaların intestinal mikrobiyotada meydana gelen değişikliklerin

Yazışma Adresi/Address for Correspondence: Negin Almasi, Hacettepe Üniversitesi Sağlık Bilimleri Fakültesi Beslenme ve Diyetetik Bölümü, Ankara, Türkiye E-posta/E-mail: negin.almasi@hacettepe.edu.tr Geliş tarihi/Received: 30.05.2021 Kabul tarihi/Accepted: 04.08 .2021 
düzenlenmesine yönelik tedavi yaklaşımlarının, tedavinin etkinliğini arttırabileceği düşünülmektedir (Carr ve ark. 2016, Carbone ve ark. 2020).

İntestinal mikrobiyota gastrointestinal sistemde yer alan çeşitli mikroorganizmalardan oluşurvekonakçıya özgüdür. Hem endojen hem de eksojen modifikasyonlara duyarlı olması nedeni ile yaşam döngüsü boyunca farklllık göstermektedir (Sekirov ve ark. 2010). Yapılan çalışmalarda intestinal mikrobiyotanın enerji homeostazı ve vücut ağırlığının düzenlenmesinde rol oynayabileceği ve yeme davranışı, anksiyete ve depresif bozukluklarla ilişkili olabileceği gösterilmiştir (De Clercq ve ark. 2016, Torres-Fuentes ve ark. 2017, Fetissov 2017, Simpson ve ark. 2020). Ayrıca, son yıllarda yapılan çalışmalarla intestinal mikrobiyotaının anoreksiya nervosanın patofizyolojisi ve tedavisindeki olası rolü de dikkat çekici hale gelmiştir (Herpertz-Dahlmann ve ark. 2017, KarakulaJuchnowicz ve ark. 2017, Ruusunen ve ark. 2019, Igudesman ve ark. 2019). Bu derlemede amaç intestinal mikrobiyotanın anoreksiya nervosanın patofizyolojisi ve tedavisindeki olası rolünün değerlendirilmesidir.

\section{Anoreksiya Nervosa Patofizyolojisinde Intestinal Mikrobiyotanın Olası Rolü}

Mikrobiyota terimi insan vücudunda yaşayan komensal, simbiyotik ve patojenik mikroorganizma topluluğunu tanımlamaktadır (Çetinbaş 2017, Lederberg ve ark. 2001). Normal insan mikrobiyotasının çok büyük bir kısmını bakteriler oluşturmaktadır ve Bacteroides ( \%20-25), Firmicutes ( \%60-65), Proteobacteria ( \%5-10) ve Actinobacteria ( \%3) filumları mikrobiyotada baskın durumdadır (Rosenbaum ve ark. 2015). İntestinal mikrobiyota besin ögelerinin sindirimi ve fermentasyonu (Rowland ve ark. 2018), kısa zincirli yağ asitleri (Morrison ve ark. 2016), $\mathrm{K}$ ve B grubu vitaminlerinin (tiamin, riboflavin, niasin, pantotenik asit, biotin, folat, B12 vitamini) sentezi (Soto-Martin ve ark. 2020, Uebanso ve ark. 2020), ksenobiyotik ve ilaç metabolizması (Li ve ark. 2016) ile immün sistemin gelişmesi ve uyarılmasında (Yoo ve ark. 2020) önemli rol oynamaktadır. Ayrıca, nöroendokrin ve metabolik yolaklar aracılığılla santral sinir sistemi, intestinal hücreler ve enterik sinir sistemi ile etkileşime girerek beyin-barsak aksını da etkilemektedir (Carabotti ve ark. 2015, Evrensel ve Ceylan 2015a). Enterik sinir sistemi gastrointestinal sistem motilitesi, sekresyonu, mukozal transport ve kan akışını düzenleyerek intestinal mikrobiyotanin kompozisyonunu etkilemektedir (Al Omran ve ark. 2014). Enterik sinir sisteminin vagus siniri aracılığı ile santral sinir sistemine bağlanması, mikrobiyotadan beyne ve santral sinir sisteminden mikrobiyotaya nörokimyasal sinyallerin oluşmasını sağlamaktadır (Carabotti ve ark. 2015).

Beyin ve intestinal mikrobiyota arasındaki etkileşim oldukça komplekstir ve bu etkileşimi kontrol eden mekanizmaların bir kısmının nöroendokrin yolaklar aracılığı ile düzenlendiği düşünülmektedir (Lyte 2013). İntestinal mikrobiyota, ya direkt olarak nörotransmitter senteziyle ya da indirekt olarak mikroorganizmaların adrenal korteksin fonksiyonunu modüle etmesiyle konakçının nörotransmitter düzeylerini etkilemektedir (Neuman ve ark. 2015). Gama-amino bütirik asit (GABA), asetilkolin, serotonin, dopamin ve histamin gibi nörotransmitterler intestinal mikrobiyota tarafından sentezlenebilmektedir (Huang ve ark. 2019). Örneğin Lactobacillus spp suşları GABA ve asetilkolin, Bifidobacterium spp suşları GABA, Escherichia spp suşları noradrenalin ve serotonin, Bacillus spp suşları noradrenalin ve dopamin, Saccharomyces suşları noradrenalin, Candida spp, Streptococcus spp ve Enterococcus spp suşları ise serotonin üretebilmektedir (Roshchina 2010). İntestinal mikrobiyota tarafindan sentezlenen nörotransmitterler, santral sinir sisteminin nörotransmitter düzeylerini etkileyerek duygu durumunun düzenlenmesinde rol oynayabilmektedir (Farzi ve ark. 2018). Anoreksiya nervosalı hastaların monoamin nörotransmitter düzeylerinin azaldığı ve bu azalmanın duygu durumu, besin alımı ve hafıza üzerinde olumsuz etkilerinin olabileceği bildirilmiştir (Riva 2016).

Intestinal bakteriler tarafından sentezlenen kısa zincirli yağ asitlerinin besin alımının düzenlenmesinde rol oynayabileceği (Byrne ve ark. 2015), anti-inflamatuar özellikleri (Tedelind ve ark. 2007) ve sempatik sinir sistemini aktive edebilecekleri gösterilmiştir (Kimura ve ark. 2011). Ayrıca, hayvan modelleri ile yapılmış araştırmalar bütiratın kan beyin bariyerinde yer alan hücrelerin aktivasyonunu değiştirerek antidepresan benzeri etkiye yol açabileceğini göstermektedir (Yamawaki ve ark. 2012, Smith 2015). Yapılan çalışmalarda anoreksiya nervosalı hastaların fekal metabolit düzeyleri değerlendirilmiş ve bütirat başta olmak üzere kısa zincirli yağ asidi düzeylerinde azalma olduğu bildirilmiştir (Mack ve ark. 2016, Borgo ve ark. 2017). Bu azalmanin anoreksiya nervosalı hastaların anksiyete ve depresyon puanlarındaki artışla ilişkili olduğu gösterilmiştir (Borgo ve ark. 2017). Ayrıca, kısa zincirli yağ asitlerinin konakçının enerji metabolizması ve iştah kontrolünde rol oynayan intestinal hormonlarının biyosentezinin düzenlenmesi üzerine etkileri ile de anoreksiya nervosa patofizyolojisinde rol oynayabileceği düşünülmektedir (Van de Wouw ve ark. 2017).

Bakteri kolonisi olmayan (germ free) steril fare ve ratlarla yürütülmüş araştırmalar, stres ve intestinal mikrobiyota arasında karşılıklı bir etkileşim olduğunu ortaya koymuştur (Foster ve ark. 2017, Mackos ve ark. 2017). Bakteri kolonizasyonu olmayan farelerin akut strese maruz birakılması Hipotalamushipofiz-adrenal (HPA) aksında aşırı yanıta yol açmış ve plazma adrenokortikotropik hormon ve kortikosteron düzeyleri çok fazla yükselmiştir. Farelerin komensal bakteriler tarafından kolonizasyonu ile artmış stres yanıtının normalizasyonu sağlanmıştır (Nobuyuki ve ark. 2004). Kronik stres intestinal mikrobiyotanın kompozisyonunda değişikliklere yol açarak HPA aksını aktive edebilmektedir (Bailey ve ark. 2011). HPA aksının hiperaktivitesi kortizol sentezine yol açabilmekte ve proinflamatuar yanıtı indükleyebilmektedir. Kortizol, intestinal kanalın ve kan beyin bariyerinin permeabilitesini arttırırak mikrobiyota ve santral sinir sistemi arasındaki etkileşimin artmasına neden olmaktadır (Foster ve ark. 2017). Aşırı fiziksel aktivitenin de benzer şekilde intestinal permeabilitede artışa yol açtığ1 gösterilmiştir (Clark ve ark. 2016). Kronik stres, artmış kortizol seviyeleri ve aşırı egzersiz anoreksiya nervosalı hastalarda da gözlenmektedir ve bu hastaların intestinal permeabilite 
geçirgenliğinin değerlendirildiği araştırma sonuçları farklılık göstermektedir (Monteleone ve ark. 2004, Mörkl ve ark. 2018). Anoreksiya nervosalı hastalarda yapılan bir çalışmada intestinal permeabilitenin azaldığı (Monteleone ve ark. 2004), başka bir çalışmada ise değişmediği gösterilmiştir (Mörkl ve ark. 2018). Bu iki çalışmada intestinal permeabilitenin değerlendirilmesinde kullanılan yöntemler farklılık göstermektedir. İlk çalışmada (Monteleone ve ark. 2014) laktuloz/mannitol testi, ikinci çalışmada (Mörkl ve ark. 2018) ise serum zonulin konsantrasyonları ölçülerek değerlendirme yapılmıştır. Deney hayvanları ile yapılan bir çalışmada ise anoreksiya nervosa modelinin kullanıldığı farelerin kolon permebilitesinde artış olduğu bildirilmiştir (Jésus ve ark. 2014).

Açlığın intestinal mikrobiyota üzerindeki olası etkilerinin değerlendirildiği insan ve hayvan çalışmalarının yer aldığı bir derleme çalışmada, açlık ve intestinal mikrobiyota arasındaki etkileşimin hangi yönde olduğunun anlaşılmasının oldukça karmaşık ve güç olduğu ortaya konmuştur (Mack ve ark. 2018). Buna karşın, intestinal mikrobiyomun iştahı, doygunluğu ve yeme davranışını etkileyebileceği düşünülmektedir (Ruusunen ve ark. 2019). Mikrobiyom aracılığıyla sentezlenen kısa zincirli yağ asitlerinin intestinal enteroendokrin hücreler tarafından salg1lanan tokluk hormonlarının (peptid YY ve glukagon benzeri peptid) sentezini kolaylaştırdığı düşünülmektedir (Alcock ve ark. 2014). Anoreksiya nervosalı hastalar üzerinde yürütülmüş araştırma sonuçları ise açlığın intestinal mikrobiyom üzerinde belirgin değişikliklere yol açabileceğini göstermektedir (Kleiman ve ark. 2015, Mack ve ark. 2016, Mörkl ve ark. 2017).

Anoreksiya nervosalı bireylerin besin alımlarını aşırı miktarda kısıtlaması enerji, karbonhidrat ve yağ alımlarının azalmasına yol açarak intestinal mikrobiyota kompozisyonunda değişikliklere neden olmaktadır (Ruusunen ve ark. 2019). Anoreksiya nervosalı bireylerin mikrobiyotasında protein ve müsin yıkıcı Verrucomicrobia ve Firmicutes filumları baskın hale gelirken, Bacteroidetes filumları azalmaktadır (Mack ve ark. 2016). Müsin yıkıcı bakteriler, barsak duvarında konumlanmış intestinal goblet hücreleri tarafından üretilen müsin ile beslenir ve bu durum intestinal bariyeri zayıflatarak barsak permeabilitesinde daha fazla artışa yol açmaktadır (Jésus ve ark. 2014, Mack ve ark. 2016). Zayıf bir intestinal bariyer ve artmış permeabilite konakçıda inflamasyonun ve immünolojik reaksiyonların tetiklenmesine yol açabilmektedir. Barsak duvarından kan dolaşımına bakteri ve lipopolisakkaritler gibi bakteri kısımlarının geçişi immün hücreleri aktive ederek proinfalamatuar sitokinlerin artmasına ve antikor oluşumuna neden olmaktadır (Kelly ve ark. 2016, Bambury ve ark. 2018). Meta-analiz çalışmalarında anoreksiyalı nervosalı bireylerin sağlıklı kontrollere kıyasla proinlamatuar sitokin düzeylerinde artış olduğu bildirilmiştir (Solmi ve ark. 2015, Dalton ve ark.. 2018). Escherichia coli (E. Coli) gibi Enterobakteriler tarafından üretilen ve $\alpha$-melanosit uyarıcı hormon ( $\alpha$-MSH) mimetiği bir antijen olan kazeinolitik proteaz (Clp) B'nin enjekte edildiği fareler tarafından anti-ClpB IgG antikorları üretilmiş ve bu antikorların $\alpha$-MSH ile çapraz reaksiyona girerek farelerin besin alımı, vücut ağırlığı ve anksiyete düzeylerini etkilediği bildirilmiştir (Tennoune ve ark. 2014). Farelerde kronik intragastrik E.coli maruziyetinin besin alımında azalmaya yol açtığı ve $\mathrm{ClpB}$ ve $\alpha-\mathrm{MSH}$ otoantikorlarının oluşumunu uyardığı gösterilmiştir. Ayrıca, anoreksiya nervosalı ve bulimiya nervosalı hastaların plazma anti-ClpB IgG antikor düzeylerinde artış olduğu saptanmıştır (Tennoune ve ark. 2014). Başka bir çalışmada da anoreksiya nervosalı hastaların da dahil olduğu yeme davranışı bozukluğu olan hastaların plazma $\mathrm{ClpB}$ konsantrasyonlarının yükseldiği ve anti-ClpB ve anti- $\alpha-M S H$ antikorları ile korele olduğu rapor edilmiştir (Breton ve ark. 2016). Bu araştırmalar bakteriyel ClpB'nin anoreksiya nervosa patofizyolojisinde rol oynayabileceğini göstermektedir.

\section{Anoreksiya Nervosalı Hastalarda İntestinal Disbiyoz}

Disbiyoz durumunda intestinal mikrobiyotanın çeşitliliği ve yararlı bakteri sayısı azalırken, patojen bakteri sayısı artmaktadır. Yapılan çalışmalarda disbiyozun inflamatuar barsak hastalıkları (İBD) (Sartor 2008, Bajer ve ark. 2017), irritabl barsak sendromu (IBS) (Rajilić-Stojanović ve ark. 2011), astım (Barcik ve ark. 2020), obezite (Walters ve ark. 2014, Altuntaş ve ark. 2017, Tekin ve ark. 2018) ve çeşitli nöropsikiyatrik bozukluklarla ilişkili olduğu gösterilmiştir (Morita ve ark. 2015, Jiang ve ark. 2015, Castro-Nallar ve ark. 2015, Keshavarzian ve ark. 2015, Aizawa ve ark. 2016, Alagöz 2017, Borgo ve ark. 2017, Strati ve ark. 2017, Vogt ve ark. 2017, Schwarz ve ark. 2018, Pulikkan ve ark. 2018). Mikrobiyotanın anksiyete ve depresyon gibi psikiyatrik bozukluklarla ilgili stres tepkisi ve stresle ilişkili davranışları modüle etmedeki rolü son yıllarda önemli bir araştırma konusu haline gelmiştir (Cryan ve ark. 2012). Bakteri kolonisi olmayan farelerin çeşitli bakteri suşları ile yapay olarak kolonizasyonu, mikrobiyotanın kompozisyonunu değiştirmekte ve anksiyete ve depresif davranışların indüklenmesinde rol oynamaktadır (Bercik ve ark. 2011, Bravo ve ark. 2011, Neufeld ve ark. 2011). Anoreksiya nervosalı hastalarla yürütülmüş araştırma sonuçları, bu hastaların intestinal mikrobiyota kompozisyonunda önemli değişiklikler olduğunu göstermiştir (Gorwood ve ark. 2016, Borgo ve ark. 2017). Bu hastaların intestinal Methanobrevibacter smithii arkeon konsantrasyonlarının daha fazla olduğu bildirilmiştir (Armougom ve ark. 2009). Buna karşın, Clostridium coccoides, Clostridium leptum ve Bacteroides fragilis filumlarının da dahil olduğu bakteri ve zorunlu anaerob bakteri düzeylerinin kontrol grubundan önemli düzeyde daha düşük olduğu rapor edilmiştir (Morita ve ark. 2015). Ayrıca, bu araştırma kısıtlayıcı tip ya da çıkartma tipi anoreksiya nervosa hastaları arasında intestinal kompozisyon bakımından önemli bir fark olmadığını ortaya koymuştur. Başka bir çalışmada ise anoreksiya nervosanın farklı türleri arasında intestinal mikrobiyom bakımından önemli farklılıklara rastlanmıştır (Mack ve ark. 2016). Kısıtlayıcı tip anoreksiya nervosa hastalarının, çıkartma tipi anoreksiya nervosa hastalarına kıyasla ağırlık kazanımı için daha fazla enerjiye ihtiyaç duymasının nedeninin, aynı miktardaki besinden enerji ekstraksiyonunda rol oynayan mikrobiyal türlerin farklılığından kaynaklandığı düşünülmektedir (Krajmalnik-Brown ve ark. 2012, Marzola ve ark. 2013). Yapılan bir çalışmada, anoreksiya nervosalı hastaların mikrobiyal çeşitliliğinin düşük olması ve taksonomik farklılıkları intestinal disbiyoz ile ilişkilendirilmiştir. Ayrıca bu 
çalışmada, intestinal disbiyozun depresyon ve yeme bozukluğu psikopatolojisi ile de ilişkili olduğu gösterilmiştir (Kleiman ve ark. 2015). Yapılan başka bir çalışmada, anoreksiya nervosalı hastaların intestinal mikrobiyota kompozisyonunda kontrol grubuna kıyasla önemli farklılıklar saptanmış ve Bacteroidetes/ Firmicutes filumlarının oranında azalma bildirilmiştir (Mack ve ark. 2016).

Literatürde yer alan çalışmaların neredeyse tamamında anoreksiya nervosalı hastaların intestinal mikrobiyota çeşitliliği ile kompozisyonun, sağlıklı bireylere ve fazla kilolu / obez kontrollere göre farklı olduğu gösterilmiştir (Armougom, ve ark. 2009, Million ve ark. 2013, Morita ve ark. 2015, Mack ve ark. 2016, Borgo ve ark. 2017, Mörkl ve ark. 2017, Hanachi ve ark. 2019) (Tablo 1).

\section{Anoreksiya Nervosalı Hastalarda Mikrobiyota Yönetimi}

İntestinal disbiyozun yeme davranış bozukluklarının etiyolojisinde önemli bir rol oynadığı düşünülmektedir ve bu nedenle barsak mikroflorasının bileşimini düzenlemeyi amaçlayan tedavi yöntemlerinin araştırılması, bu hastalıkların tedavisi için büyük önem taşımaktadır (Lam ve ark. 2017).

Anoreksiya nervosa gibi yeme bozuklukları olan hastaların tanı, tedavi ve takibi için doktor, diyetisyen ve ruh sağlığı uzmanından oluşan multidisipliner bir ekip yaklaşımı gerekmektedir (Jeffrey ve ark. 2020). Yeme davranış bozukluklarının tedavisinde diyetisyenin rolü, beslenme durumunu değerlendirmek ve düzensiz beslenme alışkanlıklarına yol açan ve optimal beslenmenin sağlanmasını ve sürdürülmesini engelleyen faktörleri belirlemek ve değerlendirmektir (McMaster ve ark. 2021). Beslenme tedavisinde; hastanın diyet yapmasinın önlenmesi, besin ögesi yetersizliklerinin düzeltilmesi, düzenli beslenme alışkanlıklarının kazandırılması ve beslenme eğitimi bireysel tedavi yaklaşımı göz önünde bulundurularak diyetisyen tarafından planlanır ve bu tedavi ile vücut ağılıklarının geri kazanımı hedeflenmektedir (Zipfel ve ark. 2015, McMaster ve ark. 2021). Yeniden ağırlık kazanımının anoreksiya nervosa hastalarının intestinal mikrobiyotasının düzenlenmesinde etkin olmadığı ve disbiyozun düzelmediği gözlenmiştir (Mack ve ark. 2016). Intestinal mikrobiyotasının bileşimi probiyotik ve prebiyotik suplementasyonu ve fekal mikrobiyota transplantasyonu ile değiştirilebilmektedir.

Probiyotik suplementasyonu, intestinal mikrobiyotanın modülasyonunda rol oynayan yaklaşımlardan biridir (Karatay 2019, Wieërs ve ark. 2020). Çalışmalar, probiyotik suplementasyonunun fonksiyonel ve inflamatuar barsak hastalıkları olan hastalarda, barsak fonksiyonunu düzenlediğini göstermiştir (Currò ve ark. 2020, Ni ve ark. 2017). Ayrıca probiyotik kullanımının hastalarda karın ağrısını azaltabileceği ve böylece hastanın diyet tedavisine uyumunu artırabileceği saptanmıştır (Didari ve ark. 2015, Sato ve ark. 2015). Probiyotik ve prebiyotik suplementasyonunun depresyon ve anksiyete tedavisindeki etkinliğinin değerlendirildiğibir sistematik derleme ve meta-analiz çalışması, probiyotik suplementasyonunun depresyon ve anksiyete tedavisinde olası bir yaklaşım olarak düşünülebileceğini ancak daha fazla randomize kontrollü klinik çalışmaya ihtiyaç duyulduğunu ortaya koymuştur (Liu ve ark. 2019). Probiyotiklerin mikrobiyomu değiştirmesinin yanı sıra bağışıklık ve beyin işlevleri üzerindeki etkileri ile iştahın düzenlenmesi ve yeme davranış bozuklukları psikopatolojisini etkileyebileceği göz önünde bulundurularak terapötik potansiyele sahip olabileceği düşünülmektedir (Foster ve ark. 2017). Bu sonuçlar probiyotik suplementasyonunun anoreksiya nervosa tedavisinde standart tedaviye ek olarak destekleyici bir tedavi yaklaşımı olarak düşünülebileceğine dikkat çekmiştir. Bütirat sentezinde rol oynayan Roseburia gibi probiyotiklerin gelecekte anoreksiya nervosa yönetiminde uygulanabileceği düşünülmektedir (Mack ve ark. 2016, Mack ve ark. 2018).

Vaka raporları ile sinırlı olsa da anoreksiya nervosada intestinal mikrobiyotanın düzenlenmesi ve disbiyozun önlenmesi amacıyla yapılan diğer yöntem fekal mikrobiyota transplantasyonudur (Evrensel ve Ceylan 2015b, Ünal 2016, De Clercq ve ark. 2019, Prochazkova ve ark. 2019). Anoreksiya nervosa hastası olan bir kadına, sağlıklı bir kadından fekal transplantasyon gerçekleştirilmiş ve hastanın enerji alımı benzer olmasına karşın zamanla vücut ağırlığında ve vücut yağ yüzdesinde artış, dinlenme enerji harcamasında ise azalma meydana gelmiştir. Ayrıca, transplantasyon sonrası hastanın intestinal mikrobiyota kompozisyonunda önemli değişiklikler ve fekal asetat ve bütirat düzeylerinde artış gözlenmiştir (De Clercq ve ark. 2019). Verrucomicrobia filumu ile kısa zincirli yağ asidi düzeylerindeki artış hastanın vücut ağırlığındaki artış ile ilişkilendirilmiştir. Kısa zincirli yağ asitlerinin besinden enerji ekstraksiyonunu arttırması, takip süresince besin alımı değişmeyen hastada meydana gelen ağırlık artışını açıklamaktadır (De Clercq ve ark. 2019). Diğer çalışmada ise şiddetli ve tekrar eden anoreksiya nevroza hastası ve ince barsaklarda aşırı bakteri çoğalması sendromu (SİBO) olan hastaya fekal mikrobiyota transplantasyonu yapılmış ve hastanın barsak bariyer fonksiyonu, mikrobiyota kompozisyonu ve bakteriyel metabolik ürünlerin düzeyleri değerlendirilmiştir (Prochazkova ve ark. 2019). Transplantasyon sonrası hastanın Bacteroidetes filumunda azalma, Firmicutes filumunda ise artış gözlenmiştir. Ayrıca, barsak bariyer fonksiyonunda iyileşme ve fekal kısa zincirli yağ asidi düzeylerinde artış olduğu bildirilmiştir. Ancak, hastanın fekal serotonin düzeylerinde azalma gözlenmiş ve klinik durumunda iyileşmeye rastlanmamıştır (Prochazkova ve ark. 2019). Bu çalışma donörün kapsamlı bir fekal mikroorganizma analizinin yapılması gerektiğini ve en uygun donörün seçilmesi gerekliliğini ortaya koymaktadır. Bu araştırmalar anoreksiya nervosalı hastalarda fekal transplantasyonun yeni bir tedavi yaklaşımı olarak düşünülebileceğini ortaya koysa da daha kapsamlı çalışmalara ihtiyaç duyulmaktadır. Ayrıca, bu vaka raporlarında fekal transplantasyon tedavisinin herhangi bir yan etkisinin olmadığı bildirilmiş olsa da diyare, konstipasyon ve enfeksiyon gibi olumsuz etkilerinin olabileceği de göz önünde bulundurulmalıdır (Agrawal ve ark. 2016). Literatürde yer alan sınırlı sayıdaki araştırma sonuçları, probiyotik suplementasyonu ve fekal transplantasyonun anoreksiya nervosa hastalarının 


\begin{tabular}{|c|c|c|c|c|c|}
\hline Kaynak & Örneklem & Amaç & $\begin{array}{l}\text { Ölçümler ve } \\
\text { Değerlendirme }\end{array}$ & $\begin{array}{l}\text { Fekal örneğin } \\
\text { toplanma zamanı }\end{array}$ & Sonuçlar \\
\hline Million, 2013 & $\begin{array}{l}15 \text { AN (BKİ 13,5 } \\
\mathrm{kg} / \mathrm{m} 2) \\
76 \text { SK (BKİ 22,4 kg/ } \\
\mathrm{m} 2) \\
38 \text { Kilolu (BKİ 27,1 } \\
\mathrm{kg} / \mathrm{m} 2) \\
134 \text { Obez (BKİ 40,0 } \\
\mathrm{kg} / \mathrm{m} 2)\end{array}$ & $\begin{array}{l}\text { Bakteri } \\
\text { konsantrasyonu } \\
\text { ile BKİ arasındaki } \\
\text { korelasyonun } \\
\text { değerlendirilmesi }\end{array}$ & $\begin{array}{l}\text {-Her grupta, bakteri } \\
\text { yaygınlığ1. } \\
\text {-Dışkıda, her filumun } \\
\text { konsantrasyonunun } \\
\text { (log10 kopya DNA / } \\
\text { ml) belirlenmesi } \\
\text { qPCR }\end{array}$ & $\begin{array}{l}\text { Hastanede yatan } \\
\text { veya hastanenin } \\
\text { beslenme } \\
\text { ünitesinde ayakta } \\
\text { tedavi gören } \\
\text { hastalardan } \\
\text { alınmıştır. Örnek } \\
\text { toplama zamanı } \\
\text { verilmemiştir. }\end{array}$ & $\begin{array}{l}\text { - Kontrol grubuna kıyasla } \\
\downarrow \text { Lactobacillus reuteri türleri } \\
\text { Obez kontrollere kıyasla } \\
\uparrow \text { Escherichia coli } \\
\uparrow \text { Archeon Methanobrevibacter } \\
\text { smithii } \\
\text { - } \uparrow \text { L. reuteri’nin dışkı } \\
\text { konsantrasyonu, } \uparrow \text { BKİ ile } \\
\text { korelasyon göstermiştir. } \\
\text { - } \uparrow \text { B. animalis, M. smithii ve } \\
\text { E. Coli, } \downarrow \text { BKİ ile korelasyon } \\
\text { göstermiştir. }\end{array}$ \\
\hline Morita, 2015 & $\begin{array}{l}25 \mathrm{AN}(\mathrm{BKI} \\
12,8 \pm 1,3 \mathrm{~kg} / \mathrm{m} 2) \\
21 \mathrm{SK}(\mathrm{BKI} \\
20,5 \pm 2,1 \mathrm{~kg} / \mathrm{m} 2)\end{array}$ & $\begin{array}{l}\text { AN hastalarının } \\
\text { fekal MB'sini } \\
\text { yaş ve cinsiyet } \\
\text { uyumlu SK'lerle } \\
\text { karşılaştırmak. }\end{array}$ & $\begin{array}{l}\text {-Bakteri sayımı (log10 } \\
\text { cells/g feçes) } \\
\text { 16Sor23S rRNA- } \\
\text { targeted-qPCR }\end{array}$ & $\begin{array}{l}\text { Katılımcılar veya } \\
\text { hastane personeli } \\
\text { tarafından yatarak } \\
\text { tedavi gören veya } \\
\text { ayakta tedavi } \\
\text { gören hastalardan } \\
2 \text { tüp }(\sim 1 \mathrm{ml} / \\
\text { tüp) alınmış } \\
\text { ancak zamanlama } \\
\text { bildirilmemiştir. }\end{array}$ & $\begin{array}{l}\text { - SK'lara kıyasla } \downarrow \text { toplam } \\
\text { bakteri ve zorunlu anaeroblar } \\
\text { (Clostridium coccoides gp, } \\
\text { Clostridium leptum subgp } \\
\text { ve Bacteroides fragilis gp, } \\
\text { Streptococcus, Lactobacillus } \\
\text { plantarum subgp). } \\
\text { - SK'lara kıyasla dişkıdaki } \\
\downarrow \text { KZYA'leri(asetik ve propiyonik } \\
\text { asit) }\end{array}$ \\
\hline Mack, 2016 & $\begin{array}{l}55 \text { Hastanede } \\
\text { tedaviye başlayan } \\
\text { AN (T1) (BKİ } \\
15,3 \pm 1,4 \mathrm{~kg} / \mathrm{m} 2) \\
44 \text { Hastaneden } \\
\text { taburcu olan AN } \\
(\mathrm{T} 2)(\mathrm{BKİ} 17,7 \pm 1,4 \\
\mathrm{kg} / \mathrm{m} 2) \\
55 \mathrm{SK}(\mathrm{BKI} \\
21,6 \pm 2,0 \mathrm{~kg} / \mathrm{m} 2)\end{array}$ & $\begin{array}{l}\text {-AN (T1 ve T2) } \\
\text { hastalarında dışkı } \\
\text { MB ve KZYA'yı SK } \\
\text { ile karşılaştırmak. } \\
\text {-AN T1 ve T2 } \\
\text { hastalarında ve } \\
\text { SK'larda diyet alımı } \\
\text { ve gastrointestinal } \\
\text { şikayetleri } \\
\text { değerlendirmek }\end{array}$ & $\begin{array}{l}\text {-AN hastaları ile } \\
\text { SK'ların intestinal } \\
\text { mikrobiyota sıklığının } \\
\text { karşılaştırılması. } \\
\text {-Bakteriyel filumların } \\
\text { nispi oranının } \\
\text { belirlenmesi } \\
\text { - } \alpha \text {-Çeşitlilik: (Chao1 } \\
\text { indeksi, Shannon } \\
\text { indeksi). } \\
\text { - } \beta \text {-Çeşitlilik } \\
\text {-Opperasyonel } \\
\text { taksanomik biriminin } \\
\text { belirlenmesi } \\
16 \text { s rRNA } \\
\text { sequencing (V4) }\end{array}$ & $\begin{array}{l}\text { Hastaneye yatış } \\
\text { yaptıktan hemen } \\
\text { sonra ve taburcu } \\
\text { olmadan önce }\end{array}$ & $\begin{array}{l}\text {-SK'lara kıyasla } \uparrow \text { müsin } \\
\text { bozucular, I, XI ve XVIII } \\
\text { Clostridium kümeleri ve } \\
\text { Bifidobacterium } \\
\downarrow \text { Roseburia spp, Coprococcus, } \\
\text { Dorea ve XIVa Clostridium } \\
\text { kümesi. } \\
\text {-AN hastalarının dışkısında } \\
\text { DZYA konsantrasyonunda artış } \\
\text { T2 hastalarında, intestinal } \\
\text { MB ve KZYA profillerindeki } \\
\text { bozukluklar ile GI semptomlarda } \\
\text { iyileşme gözlenmemiştir }\end{array}$ \\
\hline
\end{tabular}


Tablo 1 (devamı) Anoreksiyal nervosalı hastaların intestinal mikrobiyotasında meydana gelen değişiklikler

\begin{tabular}{|c|c|c|c|c|c|}
\hline Kaynak & Örneklem & Amaç & $\begin{array}{l}\text { Ölçümler ve } \\
\text { Değerlendirme }\end{array}$ & $\begin{array}{l}\text { Fekal örneğin } \\
\text { toplanma zamanı }\end{array}$ & Sonuçlar \\
\hline Borgo, 2017 & $\begin{array}{l}15 \mathrm{AN}(\mathrm{BKI} \\
13,9 \pm 2,1 \mathrm{~kg} / \mathrm{m} 2) \\
15 \mathrm{SK}(\mathrm{BKI} \\
22,1 \pm 2,6 \mathrm{~kg} / \mathrm{m} 2)\end{array}$ & $\begin{array}{l}\text { AN hastalarında } \\
\text { beslenme durumu } \\
\text { ile MB-barsak- } \\
\text { beyin aksı } \\
\text { arasındaki ilişkinin } \\
\text { incelenmesi } \\
\text { amacıyla MB } \\
\text { verilerini klinik } \\
\text { ve psikolojik } \\
\text { özelliklerle entegre } \\
\text { etmek. }\end{array}$ & $\begin{array}{l}\text { - } \alpha \text {-Çeşitlilik, } \\
-\beta \text { çeşitlilik, } \\
\text {-Operasyonel } \\
\text { taksonomik biriminin } \\
\text { sayımı, } \\
\text {-Taksonların göreceli } \\
\text { bolluğu. } \\
16 \text { s rRNA } \\
\text { Sequencing } \\
\text { (V1-V2) }\end{array}$ & $\begin{array}{l}\text { Fekal örnegin } \\
\text { toplanma zamanı } \\
\text { verilmemiştir. }\end{array}$ & $\begin{array}{l}-\uparrow \text { Enterobacteriaceae and M } \\
\text { smithii. } \\
-\downarrow \text { Roseburia, Ruminococcus and } \\
\text { Clostridium. } \\
-\downarrow \text { Fekal butyrate, ve propionate. } \\
\text {-Bütirat konsantrasyonları } \\
\text { anksiyete seviyeleri ile ters } \\
\text { orantılı } \\
\text {-Propiyonat, insülin seviyeleri } \\
\text { ve Roseburia inulinivorans'ın } \\
\text { göreceli bolluğu ile doğrudan } \\
\text { ilişkili } \\
\text {-BMI ile Bacteroides uniformis } \\
\text { ve psikopatolojik skorlar negatif } \\
\text { korelasyon } \\
\text {-BMI, en iyi şekilde intestinal } \\
\text { disbiyozunu ve metabolik } \\
\text { değişiklikleri tahmin etmiştir. }\end{array}$ \\
\hline Mörkl, 2017 & $\begin{array}{l}18 \text { AN (BKİ 15,2 } \\
\pm 1,3 \mathrm{~kg} / \mathrm{m} 2) \\
20 \text { Sporcu (BKİ } \\
22,1 \pm 1,8 \mathrm{~kg} / \mathrm{m} 2) \\
26 \mathrm{SK}(\mathrm{BKİ} \\
21,9 \pm 1,7 \mathrm{~kg} / \mathrm{m} 2) \\
22 \mathrm{Kilolu}(\mathrm{BKI} \\
27,0 \pm 1,1 \mathrm{~kg} / \mathrm{m} 2) \\
20 \text { Obez }(\mathrm{BKI} \\
34,5 \pm 4,4 \mathrm{~kg} / \mathrm{m} 2)\end{array}$ & $\begin{array}{l}\text {-AN hastalarının } \\
\text { intestinal MB'sini } \\
\text { diğer gruplarla } \\
\text { karşılaştırmak } \\
\text {-İntestinal MB'nin } \\
\text { antropometrik } \\
\text { ölçümler, toplam } \\
\text { vücut yağı ve } \\
\text { yağ dağılımı, } \\
\text { depresyon ölçekleri, } \\
\text { serum lipitleri ve } \\
\text { CRP ile ilişkisini } \\
\text { araştırmak. }\end{array}$ & $\begin{array}{l}\text { - } \alpha \text {-Çeşitlilik: (Chao1 } \\
\text { indeksi, Shannon } \\
\text { indeksi). } \\
-\beta \text {-Çeşitlilik: } \\
\text { (tartılmamış ve } \\
\text { tartılmış Unifrac } \\
\text { mesafesi) } \\
\text {-LDA puanı. } \\
16 \text { s rRNA } \\
\text { Sequencing } \\
\text { (V1-V2) }\end{array}$ & $\begin{array}{l}\text { Hastaneye yatıştan } \\
10.61 \pm 13.01 \\
\text { (SD) gün sonra } \\
\text { alınmıştır. }\end{array}$ & $\begin{array}{l}\text {-Diğer gruplar ile } \\
\text { kıyaslandığında AN hastaları ile } \\
\text { obezlerde } \downarrow \alpha \text {-çeşitlilik } \\
\text {-Sporcularda } \uparrow \alpha \text {-çeşitlilik } \\
\text {-AN hastalarında } \uparrow \\
\text { Coriobacteriaceae (LDA puanı } \\
\text { 3.5) }\end{array}$ \\
\hline
\end{tabular}

tedavisinde önemli bir rol oynayabileceğine dikkat çekse de bu tedavilerin etkinliği konusunda randomize kontrollü klinik çalışmalara ihtiyaç duyulmaktadır.

\section{Sonuç}

Anoreksiya nervoza hastalarının intestinal mikrobiyata kompozisyonunun normal ve fazla kilolu bireylere kiyasla büyük farklılıklar gösterdiği bilinmekte olup bu farklılıkların anoreksiya nervosanın bir nedeni mi yoksa bir sonucu mu olduğunun belirlenebilmesi için daha fazla araştırmaya ihtiyaç duyulmaktadır. Anoreksiya nervosada beslenme tedavisinin temelini ağırlık kazanımının sürdürülmesi ve beslenme durumunun iyileştirilmesi oluşturmaktadır. Sınırlı sayıdaki araştırma sonuçlarına göre anoreksiya nervosa hastalarının beslenme tedavisini ve yeniden ağırlık kazanımı, intestinal mikrobiyota kompozisyonunda iyileşme sağlamamıştır. Bununla birlikte, mevcut tedavi yöntemlerinin intestinal mikrobiyota üzerinde istenen değişiklikleri sağlayamaması yeni tedavi yaklaşımlarına olan ihtiyacı arttırmaktadır. İntestinal mikrobiyotanın desteklenmesinde rol oynayabilecek optimal tedavi yönteminin geliştirilebilmesi için anoreksiya nervosalı hastaların beslenme tedavi 
öncesindeki diyetleri hakkında ayrıntılı bilgi sahibi olunması, beslenme tedavi süresince farklı zamanlarda intestinal mikrobiyota kompozisyonunun değerlendirilmesi ve ek olarak fekal mikrobiyota transplantasyonu ve probiyotik suplementasyonu gibi farkli tedavi stratejilerinin denenmesi büyük önem taşımaktadır.

Yazarların Katkıları: Yazarlar çalışmaya önemli bir bilimsel katkı sağladıklarını ve makalenin hazırlanmasında veya gözden geçirilmesinde yardımcı olduğunu kabul etmiştir.

Danışman Değerlendirmesi: Dış bağımsız.

Çıkar Çatışması: Yazarlar çıkar çatışması bildirmemiştir.

Finansal Destek: Yazarlar bu çalışma için finansal destek almadiğını beyan etmiştir.

Authors Contributions: The authors attest that she has made an important scientific contribution to the study and has assisted with the drafting or revising of the manuscript.

Peer-review: Externally peer-reviewed.

Conflict of Interest: No conflict of interest was declared by the authors. Financial Disclosure: The authors declared that this study has received no financial support.

\section{Kaynaklar}

Agrawal M, Aroniadis OC, Brandt LJ, Kelly C, Freeman S, Surawicz C et al. (2016) The long-term efficacy and safety of fecal microbiota transplant for recurrent, severe, and complicated Clostridium difficile infection in 146 elderly individuals. J Clin Gastroenterol, 50:403-407.

Aizawa E, Tsuji H, Asahara T, Takahashi T, Teraishi T, Yoshida S et al. (2016) Possible association of Bifidobacterium and Lactobacillus in the gut microbiota of patients with major depressive disorder. J Affect Disord, 202:254-257

Al Omran Y, Aziz Q (2014) The brain-gut axis in health and disease. Adv Exp Med Biol, 817:135-153.

Alagöz AN (2017) Mikrobiyota ve nörodejenerasyon. J Biotechnol Strategic Health Res, 1:115-122.

Alcock J, Maley CC, Aktipis CA (2014) Is eating behavior manipulated by the gastrointestinal microbiota? Evolutionary pressures and potential mechanisms. Bioessays, 36:940-949.

APA (2013). Diagnostic and Statistical Manual of Mental Disorders, 5th Ed. Washington DC, American Psychiatric Association..

Arcelus J, Mitchell A. J, Wales J, Nielsen S (2011) Mortality rates in patients with anorexia nervosa and other eating disorders: a meta-analysis of 36 studies. Arch Gen Psychiatry, 68:724-731.

Armougom F, Henry M, Vialettes B, Raccah D, Raoult D (2009) Monitoring bacterial community of human gut microbiota reveals an increase in Lactobacillus in obese patients and Methanogens in anorexic patients. PLoS One, 4:7125.

APA (2013). Diagnostic and Statistical Manual of Mental Disorders, 5th Ed. Washington DC, American Psychiatric Association..

Bailey MT, Dowd SE, Galley JD, Hufnagle AR, Allen RG, Lyte M (2011) Exposure to a social stressor alters the structure of the intestinal microbiota: implications for stressor-induced immunomodulation. Brain Behav Immun, 25:397-407.

Bajer L, Kverka M, Kostovcik M, Macinga P, Dvorak J, Stehlikova Z et al. (2017) Distinct gut microbiota profiles in patients with primary sclerosing cholangitis and ulcerative colitis. World J Gastroenterol, 23:4548-4558.

Bambury A, Sandhu K, Cryan JF, Dinan TG (2018) Finding the needle in the haystack: systematic identification of psychobiotics. Br J Pharmacol, 175:4430-4438.
Barcik W, Boutin RCT, Sokolowska M, Finlay BB (2020) The role of lung and gut microbiota in the pathology of asthma. Immunity, 52:241-255.

Bercik P, Denou E, Collins J, Jackson W, Lu J, Jury J et al. (2011) The intestinal microbiota affect central levels of brain-derived neurotropic factor and behavior in mice. Gastroenterology, 141:599-609.

Borgo F, Riva A, Benetti A, Casiraghi MC, Bertelli S, Garbossa S et al. (2017) Microbiota in anorexia nervosa: the triangle between bacterial species, metabolites and psychological tests. PLoS One, 12: e0179739.

Bravo JA, Forsythe P, Chew MV, Escaravage E, Savignac HM, Dinan TG et al. (2011) Ingestion of Lactobacillus strain regulates emotional behavior and central GABA receptor expression in a mouse via the vagus nerve. Proc Natl Acad Sci, 108:16050-16055.

Breton J, Legrand R, Akkermann K, Järv A, Harro J, Déchelotte P, Fetissov SO (2016) Elevated plasma concentrations of bacterial ClpB protein in patients with eating disorders. Int J Eat Disord, 49:805-808.

Byrne C, Chambers E, Morrison D, Frost G (2015) The role of short chain fatty acids in appetite regulation and energy homeostasis. Int J Obes, 39:1331-1338.

Carabotti M, Scirocco A, Maselli MA, Severi C (2015) The gut-brain axis: interactions between enteric microbiota, central and enteric nervous systems. Ann Gastroenterol, 28:203-209.

Carbone EA, D’Amato P, Vicchio G, De Fazio P, Segura-Garcia C (2020) A systematic review on the role of microbiota in the pathogenesis and treatment of eating disorders. Eur Psychiatry, 64:1-40.

Carr J, Kleiman SC, Bulik CM, Bulik-Sullivan EC, Carroll IM (2016) Can attention to the intestinal microbiota improve understanding and treatment of anorexia nervosa? Expert Rev Gastroenterol Hepatol, 10:565-569.

Cass K, McGuire C, Bjork I, Sobotka N, Walsh K, Mehler PS (2020) Medical complications of anorexia nervosa. Psychosomatics, 61:625-631.

Castro-Nallar E, Bendall ML, Pérez-Losada M, Sabuncyan S, Severance EG, Dickerson FB et al. (2015) Composition, taxonomy and functional diversity of the oropharynx microbiome in individuals with schizophrenia and controls. PeerJ, 3:e1140.

Clark A, Mach N (2016) Exercise-induced stress behavior, gut-microbiotabrain axis and diet: a systematic review for athletes. J Int Soc Sports Nutr, 13:1-21.

Cryan JF, Dinan TG (2012) Mind-altering microorganisms: the impact of the gut microbiota on brain and behaviour. Nat Rev Neurosci, 13:701-712.

Currò D, Ianiro G, Pecere S, Bibbò S, Cammarota G (2017) Probiotics, fibre and herbal medicinal products for functional and inflammatory bowel disorders. Br J Pharmacol, 174:1426-1449.

Çetinbaş A (2017) Mikrobiyota. Eurasian J Med, 6:51-56.

Dalton B, Bartholdy S, Robinson L, Solmi M., Ibrahim MA, Breen G et al. (2018) A meta-analysis of cytokine concentrations in eating disorders. J Psychiatr Res, 103:252-264.

De Clercq N. C, Frissen M. N, Davids M, Groen A. K, Nieuwdorp M. (2019) Weight gain after fecal microbiota transplantation in a patient with recurrent underweight following clinical recovery from anorexia nervosa. Psychother Psychosom, 88:58-60.

De Clercq NC, Groen AK, Romijn JA, Nieuwdorp M (2016) Gut microbiota in obesity and undernutrition. Adv Nutr, 7:1080-1089.

Di Lodovico L, Mondot S, Doré J, Mack I, Hanachi M, Gorwood P (2020) Anorexia nervosa and gut microbiota: A systematic review and quantitative synthesis of pooled microbiological data. Prog Neuropsychopharmacol Biol Psychiatry, 106: 110114.

Didari T, Mozaffari S, Nikfar S, Abdollahi M (2015) Effectiveness of probiotics in irritable bowel syndrome: updated systematic review with meta-analysis. World J Gastroenterol, 21:3072-3084.

Erbay LG, Seçkin Y (2016) Yeme bozuklukları. Güncel Gastroenteroloji, 20:473-477. 
Evrensel A, Ceylan ME (2015a) Bağırsak beyin ekseni: Psikiyatrik bozukluklarda bağırsak mikrobiyotasının rolü. Psikiyatride Güncel Yaklaşımlar, 7:461-472.

Evrensel A, Ceylan ME (2015b) Fekal mikrobiyota nakli ve psikiyatrik tedavideki yeri. Anadolu Psikiyatri Derg, 16:380.

Farzi A, Fröhlich EE, Holzer P (2018) Gut microbiota and the neuroendocrine system. Neurotherapeutics, 15:5-22.

Fetissov SO (2017) Role of the gut microbiota in host appetite control: bacterial growth to animal feeding behaviour. Nat Rev Endocrinol, 13:11-25.

Foster JA, Rinaman L, Cryan JF (2017) Stress \& the gut-brain axis: regulation by the microbiome. Neurobiol Stress, 7:124-136.

Galmiche M, Déchelotte P, Lambert G, Tavolacci MP (2019) Prevalence of eating disorders over the 2000-2018 period: a systematic literature review. Am J Clin Nutr, 109:1402-1413.

Gorwood P, Blanchet-Collet C, Chartrel N, Duclos J, Dechelotte P, Hanachi $\mathrm{M}$ et al. (2016) New insights in anorexia nervosa. Front Neurosci, 10:256.

Hanachi M, Manichanh C, Schoenenberger A, Pascal V, Levenez F, Cournède $\mathrm{N}$ et al. (2019). Altered host-gut microbes symbiosis in severely malnourished anorexia nervosa (AN) patients undergoing enteral nutrition: An explicative factor of functional intestinal disorders? Clin Nutr, 38:2304-2310.

Herpertz-Dahlmann B, van Elburg A, Castro-Fornieles J, Schmidt U (2015) ESCAP Expert Paper: New developments in the diagnosis and treatment of adolescent anorexia nervosa-a European perspective. Eur Child Adolesc Psychiatry, 24:1153-1167.

Herpertz-Dahlmann B, Seitz J, Baines J (2017) Food matters: how the microbiome and gut-brain interaction might impact the development and course of anorexia nervosa. Eur Child Adolesc Psychiatry, 26:1031-1041.

Huang TT, Lai JB, Du YL, Xu Y, Ruan LM, Hu SH (2019) Current understanding of gut microbiota in mood disorders: an update of human studies. Front Genet, 10:98.

Igudesman D, Sweeney M, Carroll I. M, Mayer-Davis EJ, Bulik CM (2019) Gut-brain interactions: implications for a role of the gut microbiota in the treatment and prognosis of anorexia nervosa and comparison to type I diabetes. Gastroenterol Clin North Am, 48:343-356.

Jeffrey S, Heruc G (2020) Balancing nutrition management and the role of dietitians in eating disorder treatment. J Eat Disord, 8:64.

Jésus P, Ouelaa W, François M, Riachy L, Guérin C, Aziz M et al. (2014) Alteration of intestinal barrier function during activity-based anorexia in mice. Clin Nutr, 33:1046-1053.

Jiang H, Ling Z, Zhang Y, Mao H, Ma Z, Yin Y et al. (2015) Altered fecal microbiota composition in patients with major depressive disorder. Brain Behav Immun, 48:186-194.

Karakula-Juchnowicz H, Pankowicz H, Juchnowicz D, Valverde Piedra J, Malecka-Massalska T (2017) Intestinal microbiota-a key to understanding the pathophysiology of anorexia nervosa. Psychiatr Pol, 51:859-870.

Karatay E (2019) Mikrobiyota, prebiyotik ve probiyotikler. Anadolu Güncel Tip Dergisi, 1:68-71.

Kaye WH, Wierenga CE, Bailer UF, Simmons AN, Bischoff-Grethe A (2013) Nothing tastes as good as skinny feels: the neurobiology of anorexia nervosa. Trends Neurosci, 36:110-120.

Kelly JR, Borre Y, O’Brien C, Patterson E, El Aidy S, Deane J et al. (2016) Transferring the blues: depression-associated gut microbiota induces neurobehavioural changes in the rat. J Psychiatr Res, 82:109-118.

Keshavarzian A, Green SJ, Engen PA, Voigt RM, Naqib A, Forsyth CB et al. (2015) Colonic bacterial composition in Parkinson's disease. Mov Disord, 30:1351-1360.

Kimura I, Inoue D, Maeda T, Hara T, Ichimura A, Miyauchi S et al. (2011) Short-chain fatty acids and ketones directly regulate sympathetic nervous system via G protein-coupled receptor 41 (GPR41). Proc Natl Acad Sci USA, 108:8030-8035.
Kleiman SC, Watson HJ, Bulik-Sullivan EC, Huh EY, Tarantino LM, Bulik CM et al. (2015) The intestinal microbiota in acute anorexia nervosa and during renourishment: relationship to depression, anxiety, and eating disorder psychopathology. Psychosom Med, 77:969-981.

Krajmalnik-Brown R, Ilhan ZE, Kang DW, DiBaise JK. (2012) Effects of gut microbes on nutrient absorption and energy regulation. Nutr Clin Pract, 27:201-214.

Lam YY, Maguire S, Palacios T, Caterson ID (2017) Are the gut bacteria telling us to eat or not to eat? Reviewing the role of gut microbiota in the etiology, disease progression and treatment of eating disorders. Nutrients, 9:602.

Lederberg J, McCray AT (2001) Ome SweetOmics-A genealogical treasury of words. Scientist, 15:8.

Li H, He J, Jia W (2016) The influence of gut microbiota on drug metabolism and toxicity. Expert Opin Drug Metab Toxicol, 12:31-40.

Liu RT, Walsh RF, Sheehan AE (2019) Prebiotics and probiotics for depression and anxiety: a systematic review and meta-analysis of controlled clinical trials. Neurosci Biobehav Rev, 102:13-23.

Lyte M (2013) Microbial endocrinology in the microbiome-gut-brain axis: how bacterial production and utilization of neurochemicals influence behavior. PLoS Pathog, 9: e1003726.

Mack I, Cuntz U, Grämer C, Niedermaier S, Pohl C, Schwiertz A et al. (2016). Weight gain in anorexia nervosa does not ameliorate the faecal microbiota, branched chain fatty acid profiles and gastrointestinal complaints. Sci Rep, 6:1-16.

Mack I, Penders J, Cook J, Dugmore J, Mazurak N, Enck P (2018) Is the impact of starvation on the gut microbiota specific or unspecific to anorexia nervosa? A narrative review based on a systematic literature search. Curr Neuropharmacol, 16:1131-1149.

Mackos AR, Maltz R, Bailey MT (2017) The role of the commensal microbiota in adaptive and maladaptive stressor-induced immunomodulation. Horm Behav, 88:70-78.

Marzola E, Nasser JA, Hashim SA, Shih PA, Kaye WH (2013) Nutritional rehabilitation in anorexia nervosa: review of the literature and implications for treatment. BMC Psychiatry, 13:290.

McMaster CM, Wade T, Franklin J et al. (2021) A review of treatment manuals for adults with an eating disorder: nutrition content and consistency with current dietetic evidence. Eat Weight Disord 26:47-60.

Million á, Angelakis E, Maraninchi M, Henry M, Giorgi R, Valero R et al. (2013) Correlation between body mass index and gut concentrations of Lactobacillus reuteri, Bifidobacterium animalis, Methanobrevibacter smithii and Escherichia coli. Int J Obes, 37:1460-1466.

Monteleone P, Carratu R, Carteni M, Generoso M, Lamberti M, De Magistris $\mathrm{L}$ et al. (2004) Intestinal permeability is decreased in anorexia nervosa. Mol Psychiatry, 9:76-80

Morita C, Tsuji H, Hata T, Gondo M, Takakura S, Kawai K et al. (2015) Gut dysbiosis in patients with anorexia nervosa. PLoS One, 10:e0145274.

Mörkl S, Lackner S, Meinitzer A, Mangge H, Lehofer M, Halwachs B et al. (2018) Gut microbiota, dietary intakes and intestinal permeability reflected by serum zonulin in women. Eur J Nutr, 57:2985-2997.

Mörkl S, Lackner S, Müller W, Gorkiewicz G, Kashofer K, Oberascher A et al (2017) Gut microbiota and body composition in anorexia nervosa inpatients in comparison to athletes, overweight, obese, and normal weight controls. Int J Eat Disord, 50:1421-1431.

Morrison DJ, Preston T (2016) Formation of short chain fatty acids by the gut microbiota and their impact on human metabolism. Gut Microbes, 7:189-200.

Moskowitz L, Weiselberg E (2017) Anorexia nervosa/atypical anorexia nervosa. Curr Probl Pediatr Adolesc Health Care, 47:70-84. 
Neufeld K, Kang N, Bienenstock J, Foster JA (2011) Reduced anxiety $\searrow$ like behavior and central neurochemical change in germ凶free mice. Neurogastroenterol Motil, 23:255-264.

Neuman H, Debelius JW, Knight R, Koren O (2015) Microbial endocrinology: the interplay between the microbiota and the endocrine system. FEMS Microbiol Rev, 39:509-521.

Ni J, Wu GD, Albenberg L, Tomov VT (2017) Gut microbiota and IBD: causation or correlation? Nat Rev Gastroenterol Hepatol, 14:573-584.

Nobuyuki S, Yoichi C, Yuji A, Junko S, Naomi O, Xiao-Nian Y et al. (2004) Postnatal microbial colonization programs the hypothalamic-pituitaryadrenal system for stress response in mice. J Physiol, 558:263-275.

Okumuş FEE, Berk HÖS, Yücel B (2016) Yeme bozukluklarında tedavi motivasyonu ve yordayıcıları. Psikoloji Çalışmaları, 36:41-64.

Öyekçin DG, Şahin EM (2011) Yeme bozukluklarına yaklaşım. Türk Aile Hekimliği Dergisi, 15:29-35.

Prochazkova P, Roubalova R, Dvorak J, Tlaskalova-Hogenova H, Cermakova M, Tomasova P et al. (2019) Microbiota, microbial metabolites, and barrier function in a patient with anorexia nervosa after fecal microbiota transplantation. Microorganisms, 7:338.

Pulikkan J, Maji A, Dhakan DB, Saxena R, Mohan B, Anto MM et al. (2018) Gut microbial dysbiosis in Indian children with autism spectrum disorders. Microb Eco, 76:1102-1114.

Rajilić-Stojanović M, Biagi E, Heilig HG, Kajander K, Kekkonen RA, Tims S, De Vos WM (2011) Global and deep molecular analysis of microbiota signatures in fecal samples from patients with irritable bowel syndrome. Gastroenterology, 141:1792-1801.

Riva G (2016) Neurobiology of anorexia nervosa: serotonin dysfunctions link self-starvation with body image disturbances through an impaired body memory. Front Hum Neurosci, 10:600.

Rosenbaum M, Knight R, Leibel RL (2015) The gut microbiota in human energy homeostasis and obesity. Trends Endocrinol Metab, 26:493-501.

Roshchina VV (2010) Evolutionary considerations of neurotransmitters in microbial, plant, and animal cells. In Microbial Endocrinology: Interkingdom Signaling in Infectious Disease and Health (Eds M Lyte, PPE Freestone):17-52. New York, NY, Springer New York.

Rowland I, Gibson G, Heinken A, Scott K, Swann J, Thiele I, Tuohy K. (2018) Gut microbiota functions: metabolism of nutrients and other food components. Eur J Nutr, 57:1-24.

Ruusunen A, Rocks T, Jacka F, Loughman A. (2019) The gut microbiome in anorexia nervosa: relevance for nutritional rehabilitation. Psychopharmacology, 236:1545-1558.

Sartor RB (2008) Microbial influences in inflammatory bowel diseases. Gastroenterology, 134:577-594.

Sato Y, Fukudo S. (2015) Gastrointestinal symptoms and disorders in patients with eating disorders. Clin J Gastroenterol, 8:255-263.

Schwarz E, Maukonen J, Hyytiäinen T, Kieseppä T, Orešič M, Sabunciyan $S$ et al. (2018) Analysis of microbiota in first episode psychosis identifies preliminary associations with symptom severity and treatment response. Schizophr Res, 192:398-403.

Sekirov I, Russell SL, Antunes LCM, Finlay BB (2010) Gut microbiota in health and disease. Physiol Rev, 90:859-904.

Simpson, CA, Diaz-Arteche C, Eliby D, Schwartz OS, Simmons JG, Cowan CS (2020) The gut microbiota in anxiety and depression-A systematic review. Clin Psychol Rev, 83:101943.
Smith PA (2015) The tantalizing links between gut microbes and the brain. Nature, 526:312-314.

Solmi M, Veronese N, Favaro A, Santonastaso P, Manzato E, Sergi G, Correll CU (2015) Inflammatory cytokines and anorexia nervosa: A meta-analysis of cross-sectional and longitudinal studies. Psychoneuroendocrinology, $51: 237-252$

Soto-Martin EC, Warnke I, Farquharson FM, Christodoulou M, Horgan G, Derrien M et al. (2020) Vitamin biosynthesis by human gut butyrateproducing bacteria and cross-feeding in synthetic microbial communities. mBio, 11:e00886-20.

Strati F, Cavalieri D, Albanese D, De Felice C, Donati C, Hayek J et al. (2017) New evidences on the altered gut microbiota in autism spectrum disorders. Microbiome, 5:24.

Tedelind S, Westberg F, Kjerrulf M, Vidal A (2007) Anti-inflammatory properties of the short-chain fatty acids acetate and propionate: a study with relevance to inflammatory bowel disease. World J Gastroenterol, 13:2826.

Tekin T, Çiçek B, Konyalıgil N (2018) İntestinal mikrobiyota ve obezite ilişkisi. Sağllk Bilimleri Dergisi, 27:95-99.

Tennoune N, Chan P, Breton J, Legrand R, Chabane Y, Akkermann K et al. (2014) Bacterial ClpB heat-shock protein, an antigen-mimetic of the anorexigenic peptide $\alpha-\mathrm{MSH}$, at the origin of eating disorders. Transl Psychiatry, 4:e458-e458.

Torres-Fuentes C, Schellekens H, Dinan TG, Cryan JF (2017) The microbiota-gut-brain axis in obesity. Lancet Gastroenterol Hepatol, 2:747756

Uebanso T, Shimohata T, Mawatari K, Takahashi A. (2020) Functional roles of B区vitamins in the gut and gut microbiome. Mol Nutr Food Res, 64:e2000426.

Ünal NG (2016) Fekal Mikrobiyota Transplantasyonu. Güncel Gastroenteroloji, 20:437-441.

Van de Wouw M, Schellekens H, Dinan TG, Cryan JF (2017) Microbiota-gutbrain axis: modulator of host metabolism and appetite. J Nutr, 147:727745.

Vogt N. M, Kerby RL, Dill-McFarland KA, Harding SJ, Merluzzi AP, Johnson SC et al. (2017) Gut microbiome alterations in Alzheimer's disease. Sci Rep, $7: 13537$

Walters WA, Xu Z, Knight R (2014) Meta-analyses of human gut microbes associated with obesity and IBD. FEBS Lett, 588:4223-4233.

Wieërs, G, Belkhir L, Enaud R, Leclercq S, Philippart de Foy J.M, Dequenne I et al. (2020) How probiotics affect the microbiota. Front Cell Infect Microbiol, 9:454

Yamawaki Y, Fuchikami M, Morinobu S, Segawa M, Matsumoto T, Yamawaki S (2012) Antidepressant-like effect of sodium butyrate (HDAC inhibitor) and its molecular mechanism of action in the rat hippocampus. World J Biol Psychiatry, 13:458-467.

Yoo JY, Groer M, Dutra SVO, Sarkar A, McSkimming DI (2020) Gut microbiota and immune system interactions. Microorganisms, 8:1587.

Yüksel Altuntaş D, Batman A (2017) Mikrobiyota ve metabolik sendrom. Turk Kardiyol Dern Ars, 45:286-296.

Zipfel S, Giel KE, Bulik CM, Hay P, Schmidt U (2015) Anorexia nervosa: aetiology, assessment, and treatment. Lancet Psychiatry, 2:1099-1111. 